\title{
Lipid Accumulation Product as an Index for Visceral Obesity and Cardiovascular Risk among a Sample of Obese Egyptian Women
}

\author{
Nayera E. Hassan ${ }^{1}$, Sahar A. El-Masry ${ }^{1} * \mathbb{D}$, Gamila S. M. El-Saeed ${ }^{2}$, Mohamed S. El Hussieny ${ }^{1}$ \\ ${ }^{1}$ Department of Biological Anthropology, Medical Research Division, National Research Centre, Dokki, Giza, Egypt; ${ }^{2}$ Department \\ of Medical Biochemistry, Medical Research Division, National Research Centre, Cairo, Egypt
}

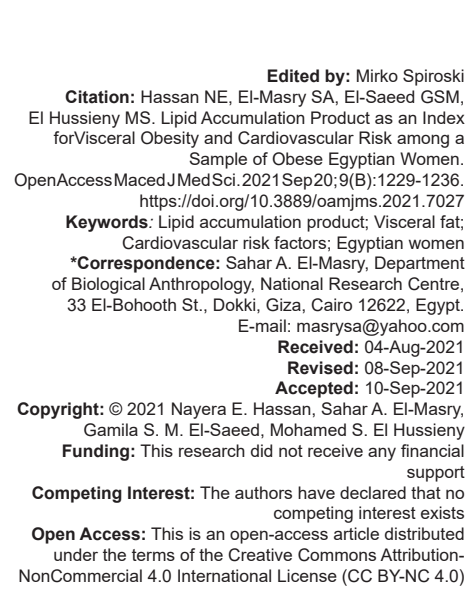

Introduction

Obesity is the fifth leading cause of death worldwide. It is a documented risk factor for large number of metabolic abnormalities as insulin resistance, dyslipidemia, higher levels of blood pressure (BP), and cardiovascular diseases (CVD) [1].

Approximately $80 \%$ of all body fat is distributed subcutaneously, accumulated largely at gluteo-femoral regions, at the back and at anterior abdominal wall. The visceral fat represents only $10-20 \%$ of the total amount of fat in male and $5-8 \%$ in females [2]. Abdominal obesity, in particularly high visceral fat, plays a crucial role in the evolution of metabolic and CVD independent of generalized obesity [3].

Multiple anthropometric measurements are used regularly for assessment of obesity such as body mass index (BMI), waist circumference (WC), and waist-to-hip ratio, but most of them cannot distinguish between visceral fat and subcutaneous fat [4].

Recently, mathematically calculated indices have been considered reliable and effective [5]. These methods are considered more applicable options, as they include formulas and biochemical measures that enable medical practice and research to enquire better tracking and risk factors prevention [6].

Lipid accumulation product (LAP) is one of these indices. It is described in the literature as sensitive and specific markers for assessment of visceral fat compared to other traditional parameters including WC and BMI. It is calculated as a combination of $W C$ and fasting triglyceride (TG). Its superiority is the simultaneous reflection of the anatomical and physiological changes of fat over accumulation in adults. According to international studies, LAP can demonstrate risk factors associated with CVD fairly well [7].

In clinical practice, imaging modalities including computed tomography (CT) and magnetic resonance imaging are considered the gold standards for assessment of visceral and subcutaneous fat. Their high costs and radiation exposure in case of CT enormously limit their widely use in medical field. Therefore, it is crucial to establish a simple and effective method for the assessment of visceral obesity in adults [8]. 
Ultrasound (US) is considered one of the most vital methods for assessing fatty body layers [9]. It is considered cheap, non-invasive, reliable, and sensitive method to estimate the visceral fat making it excellent for visceral fat assessment in all population [10].

\section{Aim of this work}

The aim of this work was to evaluate the relationship between LAP, visceral fat measurement and different cardiovascular risk factors among a sample of obese Egyptian Women.

\section{Subjects and Methods}

\section{Study subjects}

This study is retrospective cross-sectional observational study started by screening a total of 598 Egyptian women, with age ranged between 25 and 60 years who visited "Management of visceral obesity and growth disturbance unit" in the "Medical Excellence Research Centre," National research Centre, Egypt. Those with incomplete medical histories or medication records, those with chronic diseases other than hypertension or diabetes, and those who had previously received cancer treatment or were diagnosed with cancer were excluded from the study. From them, 350 obese Egyptian women, were studied for evaluation of "Visceral and Central Obesity as an Early Estimator for Obesity Health Risk: Management and Intervention." The participants were recruited from the employee in the "National Research Centre." Participants were informed about the purpose of the study and their permission in the form of written informed consent was obtained. The protocol was approved by the "Ethical Committee" of the "National Research Centre." The agreement reference number is 10/119.

All participants subjected to full clinical examination, BP, anthropometric assessment, abdominal US, and laboratory tests:

$\mathrm{BP}$ was measured on the right arm after $10 \mathrm{~min}$ of rest using an automatic BP measurement device (BP-8800C; Colin Electronics Co., Ltd., Aichi, Japan). The BP measurement was repeated if the systolic BP (SBP) was $>140 \mathrm{mmHg}$ or the diastolic BP (DBP) was $>90 \mathrm{mmHg}$. Average SBP and DBP were recorded.

\section{Anthropometric evaluation}

Anthropometric measurement was performed by trained personnel. Height, weight, waist, and hip circumferences were measured following the recommendations of the International Biological Program [11]. Height was measured to the nearest
$0.1 \mathrm{~cm}$ using a Holtainportable anthropometer, and weight was determined to the nearest $0.01 \mathrm{~kg}$ using a Seca Scale Balance, with the subject wearing minimal clothing and no shoes. WC was measured at the level of the umbilicus with the subject standing and breathing normally, the face directed forward and shoulders relaxed using non-stretchable plastic tape to the nearest $0.1 \mathrm{~cm}$. The BMI was calculated: (in meters ${ }^{2}$ )

$\mathrm{BMI}$ as weight (in kilograms) divided by height

\section{Abdominal US}

US examination to each participant was done to evaluate visceral fat at the umbilicus (USVF) in $\mathrm{cm}$. Intraabdominal fat thickness measurement was obtained using the "MedisonSonoace $\mathrm{X} 8$ " ultrasonography equipment. For visceral fat measurement, a $3.5 \mathrm{MHz}$ transducer was transversely positioned $1 \mathrm{~cm}$ above the umbilical scar on the abdominal midline, without exerting any pressure over the abdomen. Visceral fat thickness attempted corresponding to the measurement in centimeters between the internal surface of the rectus abdominis muscle and the anterior aortic wall in the abdominal midline, during expiration. These parameters were based on the previous methodological descriptions [12].

\section{Blood tests}

Participants were fasted for at least $12 \mathrm{~h}$; to get blood sample once for analysis of both FBS and lipid profile; and a blood sample was collected and analyzed under fasting conditions. The blood samples were left to clot; sera were separated by centrifugation for $10 \mathrm{~min}$ at $5000 \mathrm{rpm}$ then stored at $-80^{\circ} \mathrm{C}$ until assays. Serum concentration of fasting glucose, total cholesterol [13], TGs [14], and high-density lipoprotein- cholesterol (HDL- C) [15] was measured using commercially available kits provided by STANBIO Laboratory Inc. (1261 North Main Street Boerne Texas 78006 USA). Then total cholesterol/HDL-C ratio was calculated. Low- density lipoprotein-cholesterol (LDL- C) was calculated according to an equation developed by Friedewald [16] as follows:

LDL-C = Total cholesterol $-\mathrm{TGs} / 5+\mathrm{HDL}-\mathrm{C}$

The LAP was categorized by quartiles and analyzed the relationship.

\section{Definition of cardio vascular risk factors}

The cardio vascular risk factors were defined; according to the modified National.

Cholesterol Education Program Adult Treatment Panel III [17]; as follow: WC $>88 \mathrm{~cm}$ (for women), fasting blood sugar (FBS) $>100 \mathrm{mg} / \mathrm{dL}$; $\mathrm{BP}>130 / 85 \mathrm{mmHg}$; serum TG $>150 \mathrm{mg} / \mathrm{dL}$; and serum $\mathrm{HDL}$--cholesterol $<50 \mathrm{mg} / \mathrm{dL}$ (for women). These factors 
were referred to as visceral obesity, hyperglycemia, high BP, high TG, and low HDL-C, respectively.

\section{Defining the LAP}

LAP is defined and calculated as follows [18]:

LAP for women $=($ WC $[\mathrm{cm}]-58) \times($ TG concentration [mmol/L])

N.B.: For TGs, to convert from $\mathrm{mg} / \mathrm{dL}$ to $\mathrm{mmol} / \mathrm{L}$ multiplies by 0.01129 .

\section{Statistical analysis}

All statistical analyses were conducted with the Statistical Package for the Social Sciences (SPSS/ Windows Version 18, SPSS Inc., Chicago, IL, USA). $P$-values of all the reported results were two-tailed, and the significance level was set at $p>0.05$. Normality of data was tested using the Kolmogorov-Smirnov test, and they were not normally distributed. Descriptive statistics was expressed as mean \pm standard deviation. The participated women were divided into two groups according to the presence or absence of each cardiovascular risk factor (hypertension, high TG, low HDL-C, hyperglycemia, visceral obesity at umbilicus, and smoking). These categorical variables were expressed as numbers and percentages, and compared by using the Chi-square test.

The spearman's correlation was used to examine the significance of linear association between LAP and visceral fat on one side and the different variables. Calculation of the $4^{\text {th }}$ quartile of $L A P$ was done. The risk of presence of the $4^{\text {th }}$ quartile of LAP according to the presence of different cardiovascular risk factors was examined using odd ratio, $95^{\text {th }}$ confidence interval $(\mathrm{Cl})$ and Chi-square test. The predictive accuracy of LAP in identifying women with visceral obesity; diagnosed by US; was examined using a receiver operating characteristic (ROC) curve to assess the area under the curve (AUC), sensitivity, and specificity. Negative and positive predictive values (PPV/NPV) were calculated. Sensitivity was calculated as truepositives/(true-positives + false-negatives); specificity as true negatives/(true-negatives + false-positives). Maximal accuracy and PPVINPV closest to 1 were used for cutoff level determination

\section{Results}

This study included 350 Egyptian obese women, aged 25 up to 60 years; their mean age was $43.4 \pm 9.4$ years. In respect to the cardiovascular risk indicators, the mean $\mathrm{BP}$ was within the prehypertensive level (SBP, 128.15 $\pm 19.10 \mathrm{mmHg}$; DBP,
$83.41 \pm 11.98 \mathrm{mmHg}$ ), and the means for lipid profile were within the normal levels (TG: $122.66 \pm 54.29 \mathrm{mg} / \mathrm{dL}$, HDL: $53.44 \pm 23.34 \mathrm{mg} / \mathrm{dL})$. While, the mean BMl $\left(37.57 \pm 7.13 \mathrm{~kg} / \mathrm{m}^{2}\right)$, WC $(104.22 \pm 13.95 \mathrm{~cm})$, FBS $(103.76+37.83)$, and visceral fat $(6.20+2.16 \mathrm{~cm})$ were above the normal level. The mean LAP was $63.95 \pm 37.92$ (Table 1).

Table 1: Base line characteristics of the study participants

\begin{tabular}{|c|c|c|c|c|}
\hline \multirow[t]{2}{*}{ Variables } & \multicolumn{4}{|c|}{ Obese women $(n=350)$} \\
\hline & Mean & SD & Minimum & Maximum \\
\hline Age (years) & 43.41 & 9.41 & 25 & 60 \\
\hline \multicolumn{5}{|l|}{ Blood pressure $(\mathrm{mm} \mathrm{Hg})$} \\
\hline SBP & 128.15 & 19.10 & 90 & 200 \\
\hline DBP & 83.41 & 11.98 & 60 & 130 \\
\hline \multicolumn{5}{|l|}{ Anthropometric } \\
\hline BMI $\left(\mathrm{Kg} / \mathrm{m}^{2}\right)$ & 37.57 & 7.13 & 25 & 57 \\
\hline$W C(\mathrm{~cm})$ & 104.22 & 13.95 & 37 & 145 \\
\hline \multicolumn{5}{|l|}{ Lab } \\
\hline $\mathrm{FBS}(\mathrm{mg} / \mathrm{dL})$ & 103.76 & 37.83 & 60 & 265 \\
\hline Triglycerides $(\mathrm{mg} / \mathrm{dL})$ & 122.66 & 54.29 & 40 & 316 \\
\hline Cholesterol $(\mathrm{mg} / \mathrm{dL})$ & 201.98 & 47.33 & 50 & 381 \\
\hline $\mathrm{HDL}(\mathrm{mg} / \mathrm{dL})$ & 53.44 & 23.34 & 18 & 187 \\
\hline $\mathrm{LDL}(\mathrm{mg} / \mathrm{dL})$ & 129.27 & 44.05 & 27 & 260 \\
\hline Triglycerides/HDL & 2.62 & 1.42 & 0 & 7.06 \\
\hline Cholesterol/HDL & 4.16 & 1.32 & 0 & 8.1 \\
\hline LDL/HDL & 2.66 & 1.15 & 0 & 5.9 \\
\hline LAP (cm.mmol/L) & 63.95 & 37.92 & -8.13 & 254.4 \\
\hline \multicolumn{5}{|l|}{ US findings } \\
\hline VF at umbilicus $(\mathrm{cm})$ & 6.20 & 2.16 & 0.7 & 12.5 \\
\hline
\end{tabular}

SBP: Systolic blood pressure, DBP: Diastolic blood pressure, BMI: Body mass index, WC: Wais
circumference, FBS: Fasting blood sugar, HDL-C: High-density lipoprotein-cholesterol, LDL-C: Low-density lipoprotein-cholesterol, LAP: Lipid accumulation product, US: Ultrasound, VF: Visceral fat.

The majority of the participated women had wide WC $(88.9 \%)$ and increased visceral fat $(80.6 \%)$, while half of them were smokers $(48.8 \%)$ and had hyperglycemia $(47.4 \%)$. Hypertension was present among $42.6 \%$ of them, high TG among $26.6 \%$ and low HDL among $44.3 \%$ of them (Table 2 ).

Table 2: Frequency distribution of the components of cardiovascular risk factors by sex

\begin{tabular}{llll}
\hline Variables & Normal Range & Women $(\mathrm{n}=350)$ \\
\cline { 3 - 4 } & & $\mathrm{n}$ & $\%$ \\
\hline Hypertension & SBP/DBP>130/85 mmHg & 149 & 42.60 \\
Hyperglycemia & $>100 \mathrm{mg} / \mathrm{dL}$ & 96 & 47.4 \\
High TG & $>150 \mathrm{mg} / \mathrm{dL}$ & 155 & 26.6 \\
Low HDL & $<50 \mathrm{mg} / \mathrm{dL}$ & 321 & 44.3 \\
Wide WC & $>88 \mathrm{~cm}$ (women) & 282 & 88.9 \\
Visceral fat & $>5 \mathrm{~cm}$ & 176 & 80.6 \\
Smoking & $>3$ cigarettes/day & 48.8 \\
\hline SBP: Systolic blood pressure, DBP: Diastolic blood pressure, TG: Triglycerides, HDL-C: High-density
\end{tabular}

lipoprotein-cholesterol, WC: Waist circumference.

Spearman's correlation test revealed that LAP had highly significant positive correlations with systolic and $\mathrm{DBP}, \mathrm{BMI}, \mathrm{WC}, \mathrm{TG}$, total cholesterol, TG/ HDL, cholesterol/HDL and visceral fat at umbilicus, and significant positive correlation with age (Table 3). While visceral fat at umbilicus had highly significant positive correlations with age, systolic and DBP, BMI, WC and LAP, and significant positive correlation with TG.

The LAP was categorized by quartiles and analyzed the relationship between the $4^{\text {th }}$ quartile of the LAP (the highest values) and the different cardiovascular risk variables. Compared to that in individuals with BP $<130 / 85$, the odds of obtaining LAP $>80.74 \mathrm{~cm}$. $\mathrm{mmol} / \mathrm{L}\left(4^{\text {th }}\right.$ quartile) is 2.7 times higher in individuals with BP >130/85 $(p<0.000)$. Furthermore, the odds of obtaining a LAP $>80.74$ was 6.79 times higher in individuals with visceral fat $\geq 5 \mathrm{~cm}$ compared to that in 
Table 3: Spearman s correlations between LAP, visceral fat, and different cardiovascular risk factors

\begin{tabular}{|c|c|c|c|c|}
\hline \multirow[t]{2}{*}{ Variables } & \multicolumn{2}{|l|}{ LAP } & \multicolumn{2}{|c|}{ Visceral fat (VF) } \\
\hline & $r$ & $\mathrm{p}$ & $r$ & $\mathrm{p}$ \\
\hline Age (years) & $0.116^{*}$ & 0.033 & $0.180^{\star *}$ & 0.001 \\
\hline \multicolumn{5}{|l|}{ Blood pressure $(\mathrm{mmHg})$} \\
\hline SBP & $0.235^{\star \star}$ & 0.000 & $0.267^{\star *}$ & 0.000 \\
\hline DBP & $0.227^{\star \star}$ & 0.000 & $0.256^{\star \star}$ & 0.000 \\
\hline BMI $\left(\mathrm{Kg} / \mathrm{m}^{2}\right)$ & $0.439^{\star *}$ & 0.000 & $0.599^{\star \star}$ & 0.000 \\
\hline WC $(\mathrm{cm})$ & $0.609^{\star *}$ & 0.000 & $0.629^{\star \star}$ & 0.000 \\
\hline \multicolumn{5}{|l|}{ Lab } \\
\hline $\mathrm{FBS}(\mathrm{mg} / \mathrm{dL})$ & 0.066 & 0.229 & 0.032 & 0.558 \\
\hline Triglycerides (mg/dL) & $0.821^{\star *}$ & 0.000 & $0.129^{*}$ & 0.017 \\
\hline Cholesterol (mg/dL) & $0.154^{\star \star}$ & 0.005 & 0.084 & 0.123 \\
\hline $\mathrm{HDL}(\mathrm{mg} / \mathrm{dL})$ & -0.060 & -0.280 & 0.074 & 0.173 \\
\hline LDL (mg/dL) & -0.030 & -0.589 & 0.023 & 0.673 \\
\hline Triglycerides/HDL & $0.730^{* *}$ & 0.000 & 0.096 & 0.080 \\
\hline Cholesterol/HDL & $0.145^{\star *}$ & 0.008 & 0.041 & 0.452 \\
\hline LDL/HDL & 0.001 & 0.988 & 0.000 & 0.999 \\
\hline LAP (cm.mmol/L) & & & $0.411^{* *}$ & 0.000 \\
\hline \multicolumn{5}{|l|}{ US findings } \\
\hline $\begin{array}{l}\text { VFA at } \\
\text { umbilicus }\left(\mathrm{cm}^{2}\right)\end{array}$ & $0.412^{\star *}$ & 0.000 & & \\
\hline
\end{tabular}

individuals with visceral fat $<5 \mathrm{~cm}(\mathrm{p}<0.000)$. Moreover, the results showed that the presence or absence of hyperglycemia or low HDL was insignificantly associated with the LAP (Table 4).

Table 4: Risk of LAP $(>80.74)$ according to the different cardiovascular risk factors

\begin{tabular}{lllll}
\hline & OR & $95 \% \mathrm{Cl}$ & & $\mathrm{p}$ \\
\hline Hypertension & 2.702 & 1.608 & 4.540 & $0.000^{\star *}$ \\
High TG & 34.244 & 17.626 & 66.532 & $0.000^{\star *}$ \\
Low HDL & 1.482 & 0.903 & 2.433 & 0.119 \\
Hyperglycemia & 1.394 & 0.852 & 2.281 & 0.187 \\
VF at umbilicus (cm) & 6.785 & 2.391 & 19.256 & $0.000^{\star *}$ \\
Smoking & 0.283 & 0.077 & 1.037 & $0.044^{*}$ \\
\hline TG: Triglycerides, HDL-C: High-density lipoprotein-cholesterol, VF: Visceral fat. $\mathrm{p}<0.05=$ significant \\
difference, $\mathrm{p}<0.01=$ highly significant difference
\end{tabular}

Depending on the visceral fat as a standard for classification of visceral obesity ( $>5 \mathrm{~cm}$ for women), revealed that the AUCs of LAP was $0.752(95 \%$ $\mathrm{Cl} 0.697-0.806)$ in women with statistical significance $(p=0.000)$ (Figure 1). The cutoff point of LAP was found to be 61.69 for centrally obese women; using ROC analysis; with sensitivity $68 \%$ and specificity $75 \%$ and PPV/NPV 1.05 and accuracy $71.5 \%$

\section{Discussion}

Obesity is a significant public health problem with a reduced quality of life, multiple comorbidities, and multicausal mortality [19]. The frequency of obesity related cardiovascular risk factors has significantly increased both in developing and developed countries [20]. In defining obesity and its relevance in predicting cardiovascular risks, concern has changed from central obesity to visceral obesity [21].

Multiple indices are used to determine general and central obesity in clinical practice. Although BMI is the most widely used parameter for assessment of obesity, it is an indicator of general obesity rather

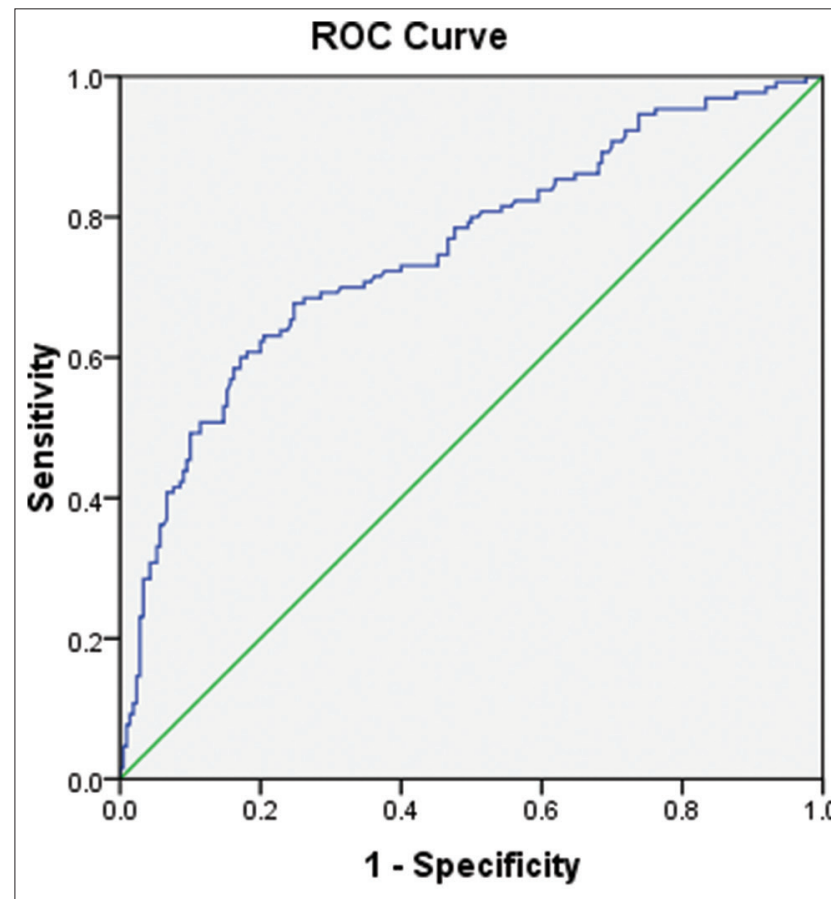

Diagonal segments are produced by ties.

Area Under the Curve

Test Result Variable (s):Lipid Accumulation Product

Area Std. Error ${ }^{\mathrm{a}} \quad$ Asymptotic Sig. $^{{ }^{\mathrm{b}}} \quad$ Asymptotic $95 \%$ Confidence Interval \begin{tabular}{lllll}
\cline { 3 - 4 } & & Lower Bound & Upper Bound \\
\hline 0.752 & 0.028 & 0.000 & 0.697 & 0.806 \\
\hline
\end{tabular}

Figure 1: Receiver operating characteristic curve for lipid accumulation product to identify visceral obesity among Egyptian women. The area under the curve is $0.752(p<0.000)$ with $95 \%$ confidence intervals ranged between 0.697 and 0.806 . The straight line is the line of identity, corresponding to an area under the curve of $50 \%$

than central obesity [22]. Clinicians are encouraged to use BMI and WC as monitoring tools for assessment of obesity in adults and children [19]. WC is better than $\mathrm{BMI}$ in evaluating visceral fat distribution and in anticipating CVD [22].

The LAP is one of the anthropometric indices that is built on a combination of two low-cost measurements, WC and serum TG implicating an over accumulation of lipids over time [1]. LAP can surmount BMI in the anticipation of $C V D$ risk with positive correlation between it and long-standing CVD incidence in CVD-free Caucasian adults as documented by Kyrou [23].

Studies have shown that LAP Index is linked with hypertension, type-2 diabetes mellitus (T2DM), metabolic syndrome, and CVD. Most of these studies suggest that LAP is a strong indicator for prediction of a worse metabolic profile and CVD when matched with other long used anthropometric indices [1].

In the current study, LAP and visceral fat at umbilicus had highly significant positive correlations with BMI and WC. Evans [24] study showed that LAP index is a more sensitive tool than BMI and WC in the anticipation of cardio-metabolic risk among T2DM patients. Similar results were documented by Gao [25]. 
Measurements of visceral fat area of the abdomen were evaluated thoroughly for its value in anticipating the presence of cardiovascular risk factors [21]. CT is considered to be the "golden standard," being able to exactly differentiate visceral fat from subcutaneous fat in anybody region. However, its great cost, the necessity of sophisticated machine, expert people and the exposure of the individual to radiation are the main restrictions for its use in routine practice and in observational studies [26]. US is considered one of the most hopeful methods for assessment of fat layers in the body [9].

There have been many studies on LAP and chronic metabolic and cardiovascular diseases, but the relationship between LAP and visceral fat measurement needs further assessment. Moreover, an index such as LAP can have different results based on ethnicity, and this study is valuable because it analyzes the relationship between LAP, visceral fat measurement and cardiovascular risk factors in Egyptian adults.

Hypertension is one of the most critical public health problems worldwide with an increased prevalence in last year's [27]. It is considered as a leading risk factor for CVD [28]. High levels of visceral fat were observed in males and females suffering from arterial hypertension [2].

In current results both LAP and visceral fat at umbilicus had highly significant positive correlations with systolic and DBP. Ian [8] found a significant relationship between LAP and hypertension risk in Han Chinese adults. Similar results were found in Japanese population done by Wakabayashi [29] in Mongolians population by Gao [25].

The TG/HDL-C ratio is an unsophisticated tool to ascertain patients at increased risk for insulin resistance and CVD. It is used to determine subjects at risk and vary across ethnicity and race [7]. Ioachimescu [30] and Bruna [1] also detected correlations with LAP Index and fasting glucose, HDL-C and SBP in both general population and in patients at higher cardiovascular risk. In the current study, LAP had highly significant positive correlations with TG, total cholesterol, TG/HDL, and cholesterol/HDL.

Obesity is intimately related with a higher incidence of type 2 diabetes and ii associated with the development of diabetic complications [31]. It has been found that subjects with increased visceral fat have greater degree of insulin resistance [32]. Visceral fat is considered a metabolically active endocrine organ, secreting multiple pro-inflammatory adipokines with subsequent occurrence of a number of cardio-metabolic disorders [32]. LAP can be used as a non-invasive tool for assessing insulin resistance and diabetes as it can reflect visceral fat accumulation [33].

Pontes [34] conducted that LAP was a better indicator of glucose imbalance and a stronger predictor of DM than BMI. Flavia [35] had confirmed that LAP is sensitive to identify impairment related to glucose metabolism even after correction for drug use. However, in our study, the results showed that the presence or absence of hyperglycemia is insignificantly associated with the LAP.

Freedman [36] and Snijder [37] have found that visceral obesity determined by WC is more strongly associated with cardiovascular risk factors than BMI. Porter [38] and McLaughlin [39] identified that several CVD risk factors, including hypercholesterolemia and low HDL-C, were associated only with VAT volume change but not with SAT volume change. Our outcome documented that visceral fat at umbilicus had highly significant positive correlations with TG and LAP.

In many populations, the body composition differs substantially according to several ethnics, and most of the studies that evaluated LAP Index were made among Americans, European, and Eastern people. In this study, we use $5 \mathrm{~cm}$ as the best cutoff points of measurement of visceral fat by US for women as concluded by Hassan [40] study done on a sample of adult Egyptian women. We use it to document the cutoff of LAP among our subjects.

Wakabayashi [29] 2014 evaluated 10,170 Japanese workers (35-40 years old) and proposed cutoff values for the LAP index of $21.1 \mathrm{~cm} . \mathrm{mmol} / \mathrm{l}$ and $37.2 \mathrm{~cm} . \mathrm{mmol} / \mathrm{l}$ for women and men, respectively.

Nascimento [41] found a high cutoff point through using an ROC curve in a cross-sectional study conducted on 78 women aged 18-42 years who presented polycystic ovarian syndrome and were attended at a university hospital in Brazil. They showed that all cardiovascular risk markers presented a higher chance of being altered when the LAP index was above the cutoff value of $37.9 \mathrm{~cm} . \mathrm{mmol} / \mathrm{l}$. This higher value may have been found because women with polycystic ovarian syndrome already present higher cardiovascular risk than that of the general population. Finally, in a regional hospital in southern Taiwan, Chiang [42] evaluated 513 individuals and showed that the optimal cutoff for the LAP index was $28.4 \mathrm{~cm}$. $\mathrm{mmol} / \mathrm{l}$, for both sexes.

The cutoff point of LAP in our study was found to be $61.69 \mathrm{~cm} . \mathrm{mmol} / \mathrm{l}$ for centrally obese women with sensitivity $68 \%$ and specificity $75 \%$ and accuracy $71.5 \%$.

In conclusion, the results from the present study showed that the LAP index presented good correlations with visceral fat and cardiovascular risk factors. The cutoff point of LAP 61.69 can be used to predict visceral obesity among Egyptian women.

It proves the assumption that it is a practical indicator for detecting interactions between excess body fat and its related risk factors. Therefore, it will be helpful in primary medical care services that face 
financial difficulty that hinder access to cardiovascular risk markers.

\section{Limitation of this study}

This study was done on women only. In future, further research should be done on men, to have equation for each sex.

\section{Acknowledgments}

We would like to acknowledge our institute "National Research Centre'; Egypt;" without their support this study could not be done. The authors are also grateful to everybody participated in this study; the employers of our institute who were the participants of this study, the technicians who helped in the laboratory analysis and the doctors who participated in collection of the data'. Without their help, this study could not have been completed.

\section{Author Contribution}

Nayera E. Hassan and Mohamed S. El Hussieny, designed the study; Nayera E. Hassan, supervisor on anthropological assessment; Sahar A. El-Masry performed the statistical analysis and publication process; Mohamed S. El Hussieny responsible for radiological assessment of visceral obesity; Gamila S. M. El-Saeed responsible for laboratory investigations. All authors contributed to the collection of references, drafting of the article, and final approval of the version to be submitted. All the authors have accepted responsibility for the entire content of this submitted manuscript and approved submission.

\section{References}

1. Vieira BA, Sauer $P$, Marcadenti A, Piovesan $\mathrm{CH}$. Association between LAP index (lipid accumulation product) and metabolic profile in hospitalized patients. Nutr Hosp 2015;31(6):2771-4. http://doi.org/10.3305/nh.2015.31.6.8957 PMid:26040394

2. Pinho $C P$, da Silva Diniz A, de Arruda IK, Leão AP, Rodrigues EC Factors associated with the concentration of visceral and subcutaneous fat. Health Care Curr Rev 2017;5:4

3. Jung $\mathrm{CH}$, Rhee $\mathrm{EJ}$, Kwon $\mathrm{H}$, Chang $\mathrm{Y}$, Ryu S, Lee WY Visceral-to-subcutaneous abdominal fat ratio is associated with nonalcoholic fatty liver disease and liver fibrosis. Endocrinol Metab 2020;35(1):165-76. http://doi.org/10.3803/

\section{EnM.2020.35.1.165}

PMid:32207277

4. Tehrani FR, Minooee S, Azizi F. Comparison of various adiposity indexes in women with polycystic ovary syndrome and normoovulatory non-hirsute women: A population based study. Eur J Endocrinol. 2014;171(2):199-207. http://doi.org/10.1530/ EJE-14-0094

PMid:24816947

5. Ray L, Ravichandran K, Nanda SK. Comparison of lipid accumulation product index with body mass index and waist circumference as a predictor of metabolic syndrome in Indian population. Metab Syndr Relat Disord. 2018;16(5):240-5. http:// doi.org/10.1089/met.2017.0119

PMid:29648916

6. Mario FM, Graff SK, Spritzer PM. Adiposity indexes as phenotype-specific markers of preclinical metabolic alterations and cardiovascular risk in polycystic ovary syndrome: A cross-sectional study. Exp Clin Endocrinol Diabetes. 2017;125(5):307-15. http://doi.org/10.1055/s-0042-119524 PMid:28201826

7. Kwon SH, Han AL. The correlation between the ratio of viscera fat area to subcutaneous fat area on computed tomography and lipid accumulation product as indexes of cardiovascular risk. J Obes Metab Syndr. 2019;28(3):186-93. http://doi.org/10.7570/ jomes.2019.28.3.186

PMid:31583383

8. Song J, Zhao Y, Nie S, Chen X, Wu X, Mi J. The effect of lipid accumulation product and its interaction with other factors on hypertension risk in Chinese Han population: A cross-sectional study. PLoS One. 2018;13(6):e0198105. http://doi.org/10.1371/ journal.pone. 0198105 PMid:29874254

9. Meuller W, Maughan RJ. The need for a novel approach to measure body composition: Is ultrasound an answer? $\mathrm{Br}$ J Sports Med. 2013;47(16):1001-2. http://doi.org/10.1136/ bjsports-2013-092882

PMid:23962880

10. Sakuno T, Tomita LM, Tomita CM, de Carlos Back Giuliano I, Ibagy A, et al. Lisiane Schilling Poeta. Sonographic evaluation of visceral and subcutaneous fat in obese children. Radiol Bras. 2014;47(3):149-53

11. Hiernaux J, Tanner JM. Growth and physical studies. In: Weiner JS, Lourie SA, editors. Human Biology: A Guide to Field Methods. London, Oxford, UK: IBP, Blackwell Scientific Publications; 1969.

12. Ribeiro-Filho FF, Faria AN, Azjen S, Zanella MT, Ferreira SR Methods of estimation of visceral fat: advantages of ultrasonography. Obes Res. 2003;11(12):1488-94. http://doi. org/10.1038/oby.2003.199 PMid:14694213

13. Allain CC, Poon LS, Chen CSG, Richmond W, Fu PC. Enzymatic determination of total serum cholesterol. Clin Chem. 1974;20(4):470-5. PMid:4818200

14. Fossati $P$, Prencipe L. Serum triglycerides determination colorimetrically with an enzyme that produces hydrogen peroxide. Clin Chem. 1982;28:2077-88. PMid:6812986

15. Burstein M, Scholnick HR, Morfin R. Rapid method for the isolation of lipoproteins from human serum by precipitation with polyanions. J Lipid Res. 1970;11(6):583-95.

PMid:4100998

16. Friedewald WI, Levy RI, Fredrickson DS. Estimation of the concentration of low density lipoprotein cholesterol in plasma without use of preparative ultracentrifuge. Clin Chem. 
1972;18(6):499-502.

PMid:4337382

17. Expert Panel on Detection, Evaluation, and Treatment of High Blood Cholesterol in Adults. Executive summary of the Third Report of the National Cholesterol Education Program (NCEP) expert panel on detection, evaluation, and treatment of high blood cholesterol in adults (Adult Treatment Panel III). JAMA. 2001;285(19):2486-97. http://doi.org/10.1001/ jama.285.19.2486

PMid:11368702

18. Amato MC, Giordano C, Galia M, Criscimanna A, Vitabile S, Midiri $\mathrm{M}$, et al. Visceral adiposity index: A reliable indicator of visceral fat function associated with cardiometabolic risk. Diabetes Care. 2010;33(4):920-2.

PMid:20067971

19. Woldemariam MM, Evans KD, Butwin AN, Volz KR Measuring abdominal visceral fat thickness with sonography: A methodologic approach. J Diagn Med Sonogr 2018;34(2):91-6.

20. Seravalle G, Grassi G. Obesity and hypertension. Pharmacol Res. 2017;122:1-7. https://doi.org/10.1016/j.phrs.2017.05.013 PMid:28532816

21. Oh $\mathrm{YH}$, Moon JH, Kim HJ, Kong MH. Visceral-to-subcutaneous fat ratio as a predictor of the multiple metabolic risk factors for subjects with normal waist circumference in Korea. Diabetes Metab Syndr Obes. 2017;10:505-11. https://doi.org/10.2147/ DMSO.S150914

PMid:29270027

22. HajianTilaki K, Heidari B. Is waist circumference a better predictor of diabetes than body mass index or waisttoheight ratio in Iranian adults? Int J Prev Med. 2015;6:5. https://doi. org/10.4103/2008-7802.151434 PMid:25789140

23. Kyrou I, Panagiotakos DB, Kouli GM, Georgousopoulou E, Chrysohoou C, Tsigos C, et al. Lipid accumulation product in relation to 10-year cardiovascular disease incidence in Caucasian adults: The ATTICA study. Atherosclerosis. 2018;279:10-6. https://doi.org/10.1016/j.atherosclerosis.2018.10.015 PMid:30366186

24. Adu EA, Obirikorang C, Acheampong E, Kwakye AS, Fokuoh F, Obirikorang $\mathrm{Y}$, et al. Lipid accumulation product (LAP) index as a potential risk assessment for cardiovascular risk stratification among Type II diabetes mellitus in a Ghanaian population: A cross-sectional study. Cogent Med. 2019;6:1639880. https:// doi.org/10.1080/2331205X.2019.1639880

25. Gao X, Wang G, Wang A, Xu T, Tong W, Zhang Y. Comparison of lipid accumulation product with body mass index as an indicator of hypertension risk among Mongolians in China. Obes Res Clin Pract. 2013;7(4):e308-14. https://doi.org/10.1016/j. orcp.2012.02.002 PMid:24306160

26. Roriz C, Karla A, Passos S, Carlos L, de Oliveira C, Carolina, et al. Anthropometric clinical indicators in the assessment of visceral obesity: An update. Nutr Clín Diet Hosp. 2016;36(2):168- 79. https://doi.org/10.12873/362carneirororiz

27. Campbell NR, Lackland DT, Niebylski ML, World Hypertension League Committee, International Society of Hypertension Executive Committee. High blood pressure: Why prevention and control are urgent and important: A 2014 fact sheet from the world hypertension league and the international society of hypertension. J Clin Hypertens (Greenwich). 2014;16(8):551-3. https://doi.org/10.1111/jch.12372

PMid:25040331

28. Bundy JD, He J. Hypertension and related cardiovascular disease burden in China. Ann Glob Health. 2016;82(2):227-33. https://doi.org/10.1016/j.aogh.2016.02.002

\section{PMid:27372527}

29. Wakabayashi I, Daimon T. A strong association between lipid accumulation product and diabetes mellitus in Japanese women and men. J Atheroscler Thromb. 2014;21(3):282-8. https://doi. org/10.5551/jat.20628

\section{PMid:24304961}

30. Ioachimescu AG, Brennan DM, Hoar BM, Hoogwerf BJ. The lipid accumulation product and all-cause mortality in patients at high cardiovascular risk: A PreCIS database study. Obesity (Silver Spring). 2010;18(9):1836-44. https://doi.org/10.1038/ oby.2009.453

PMid:20035284

31. Tobias DK, Pan A, Jackson CL, O'Reilly EJ, Ding EL, Willett WC, et al. Body-mass index and mortality among adults with incident Type 2 diabetes. N Engl J Med. 2014;370(14):233-44. https:// doi.org/10.1056/NEJMc1401876

PMid:24693908

32. Sun K, Lin D, Feng Q, Li F, Qi Y, Feng W, et al. Assessment of adiposity distribution and its association with diabetes and insulin resistance: A populationbased study. Diabetol Metab Syndr. 2019;11:51. https://doi.org/10.1186/s13098-019-0450-x PMid:31297161

33. Klisic A, Kotur-Stevuljevic J, Kavaric N, Matic M. Relationship between cystatin $\mathrm{C}$, retinol-binding protein 4 and Framingham risk score in healthy postmenopausal women. Arch Iran Med. 2016;19:845851.

PMid:27998159

34. Pontes AG, Rehme MF, Martins AM, Micussi MT, Maranhão TM, Pimenta WP, et al. Insulin resistance in women with polycystic ovarysyndrome:relationshipwithanthropometricand biochemical variables. Rev Bras Ginecol Obstet. 2012;34(2):74- 9. http://doi. org/10.1590/s0100-72032012000200006

PMid:22437766

35. De Conti Cartolano F, Pappiani C, de Freitas MC, Neto AM, Carioca AA, et al. Is Lipid Accumulation Product Associated with an Atherogenic Lipoprotein Profile in Brazilian Subjects? Arq Bras Cardiol. 2018;110(4):339-47. http://doi.org/10.5935/ abc. 20180054

PMid:29791572

36. Freedman DS, Thornton JC, Pi-Sunyer FX, Heymsfield SB Wang J, Pierson RN, et al. The body adiposity index (hip circumference $\div$ height 1.5 ) is not a more accurate measure of adiposity than is BMI, waist circumference, or hip circumference. Obesity. 2012;20(12):2438-44. http://doi.org/10.1038/ oby. 2012.81 PMid:22484365

37. Snijder MB, Nicolaou M, van Valkengoed IG, Brewster LM, Stronks K. Newly proposed body adiposity index (Bai) by Bergman et al. is not strongly related to cardiovascular health risk. Obesity. 2012;20(6):1138-9. http://doi.org/10.1038/ oby.2011.338 PMid:22627979

38. Porter SA, Massaro JM, Hoffmann U, Vasan RS, O'Donnel CJ, Fox CS. Abdominal subcutaneous adipose tissue: A protective fat depot? Diabetes Care. 2009;32(6):1068-75. http://doi. org/10.2337/dc08-2280 PMid: 19244087

39. McLaughlin T, Lamendola C, Liu A, Abbasi F. Preferential fat deposition in subcutaneous versus visceral depots is associated with insulin sensitivity. J Clin Endocrinol Metab. 2011;96(11):E1756-60. http://doi.org/10.1210/jc.2011-0615 PMid:21865361

40. Nayera H, El-Masry S, El Hussieny M, El-Banna R, El Sherity S, Ebrahim E, et al. Visceral fat cut-off points for a sample of 
Egyptian adults. Maced J Med Sci. 2013;6(4):344-9. http://doi. org/10.3889/MJMS.1857-5773.2013.0333

41. Nascimento JX, Chein MB, de Sousa RM, dos Santos Ferreira A, Navarro PA, Brito LM. Importance of lipid accumulation product index as a marker of CVD risk in PCOS women. Lipids Health Dis. 2015;14:62. http://doi.org/10.1186/s12944-015-0061-y
PMid:26104466

42. Chiang JK, Koo M. Lipid accumulation product: A simple and accurate index for predicting metabolic syndrome in Taiwanese people aged 50 and over. BMC Cardiovasc Disord. 2012;12:78. http://doi.org/10.1186/1471-2261-12-78

PMid:23006530 